\title{
Relationship between Night shift work, Eating Habits and BMI among Nurses in Lebanon
}

Zeinab Samhat ( zeinabsamhat@hotmail.com)

Universite Saint-Esprit de Kaslik https://orcid.org/0000-0001-8873-9667

Randa Attieh

Universite Saint-Esprit de Kaslik

Yonna Sacre

Universite Saint-Esprit de Kaslik

\section{Research article}

Keywords: Night shift work, eating habits, body mass index, nurses, Lebanon

Posted Date: January 29th, 2020

DOI: https://doi.org/10.21203/rs.2.16152/v2

License: () (i) This work is licensed under a Creative Commons Attribution 4.0 International License. Read Full License

Version of Record: A version of this preprint was published at BMC Nursing on April 15th, 2020. See the published version at https://doi.org/10.1186/s12912020-00412-2. 


\section{Abstract}

Background The objective of this cross-sectional study was to evaluate the relationships between night shift work, eating habits and body mass index (BMI) among Lebanese nurses.

Methods A total of 307 nurses were randomly selected from five hospitals located in Beirut. Data about demographic and professional characteristics, anthropometric measures, dietary habits and intakes were collected through a validated questionnaire. To study the relationship between night shift work, eating habits and BMI, chi-square test, $\mathrm{t}$-test and logistic regressions were used.

Results The majority of nurses (78. 2\%) had irregular meals timing with a significant decrease in the number of complete meals consumed during the day and an increase in the number of snacks consumed during night $(p<0.05)$. The most consumed snacks during night shifts were sweets and potato chips. The findings highlighted that BMI and waist circumference significantly increased with the number of years of work $(r=0.175 ; p<0.05)$ and the cumulative number of night shifts hours over the entire work history $(r=0.135 / p<0.05)$.

Conclusion: Night shift work is positively associated with abnormal eating patterns and BMI among Lebanese nurses. However the increase in BMI is not related to eating habits.

\section{Introduction}

Night shift work is frequent in some professional sectors such as in hospitals, retail sectors, and transportation. According to the Lebanese labour code, night shift work is defined as any job performed between $8 \mathrm{pm}$ and 5 am during summer and between $7 \mathrm{pm}$ and 6 am during winter, at least two times per week [1]. Night shift work may negatively affect health $[2,3]$. Several studies have confirmed that there is a direct relationship between night work and heart disease, altered lipid profile, weight gain, and metabolic syndrome $[4,5,6]$. Working during night affects health since it disrupts circadian rhythms and eating habits, compromise cognitive ability, cause fatigue, lack of sleep and digestive problems. These factors can lead to weight gain, obesity, cardiovascular disease, metabolic disorders, type 2 diabetes and breast cancer $[7,8,9,10]$. Night shift work is associated with an increase in BMI and can lead to overweight and obesity $[11,12,13,14,15,16]$. Cumulative night shift work is strongly related to an increase in BMI, waist circumference $[17,18,19]$, hip circumference and waist to hip ratio [20]. Weight gain associated with night shift work may be the result of an excess of calorie intake and a lack of physical activity during night $[21,22]$. For example, night shift nurses have irregular meals timing, snack more, have some preference for high fat and high sugar foods and do not practice any physical activities outside their occupation because of the fatigue associated with the nature of their work [23, 24, 15, 25]. The frequent consumption of high sugar and high fat foods and the lack of physical activity observed among night shift nurses can lead to an accumulation of subcutaneous fat [21, 22] with subsequent increase in body weight $[26,25]$. To our knowledge, no studies have yet been published and/or carried out on night shift work and its effect on eating habits among nurses in Lebanon. Therefore, this study allowed us to add some values to the scientific literature by evaluating the impact of night shift work on the diet of Lebanese nurses and to determine if there is a possible relationship between night shift work, diet and an increase in BMI.

\section{Methods}

\subsection{Participants selection and recruitment}

This cross-sectional study was performed between January and June 2017. A total of 334 nurses were randomly selected from five hospitals in Beirut. They were anonymously interviewed using a questionnaire. Participants were males and females, aged 24-45 years, with at least two years experiences and without any health problems. Twenty-seven nurses declined to participate because they did not have enough time to fill the questionnaire. Thus the final number of participants was 307 nurses. A written informed consent was obtained from the participants prior to their participation.

\subsection{Data collection}

A total of 307 individual interviews were conducted using a pre-tested, face-to-face questionnaire adapted from two validated questionnaires including the Standard Shiftwork Index questionnaire [27] and the EPIC-Norfolk Food Frequency Questionnaire (FFQ) [28]. The questionnaire was completed during working hours. All nurses coming across was asked to participate to the study. Only those who had given their consent, completed the questionnaire. For confidentiality reasons all respondents have been anonymised. Information about age, sex, number of years of experience, number of night shift hours per month, level of physical activity, BMI, waist circumference, number and type of meals consumed and meal times were collected. Dietary intakes were estimated by a FFQ consisting of seven food groups and five beverage items : starch, fruits, vegetables, milk and dairy products, meat, fat, sweets, caffeinated drinks, fresh juices, commercial juices, soda and energy drinks. The categories of frequency of use were: never or rarely, once per day, two to three times per day, four to five times per day, six and more times per day [28]. The frequencies used to measure the daily intake of each food and beverage portion were: never or rarely $=0$, once per day $=1$, two to 3 times per day $=2.5$, four to five times per day $=4.5$ and six and more times per day $=6$. The frequencies of daily consumption were compared to the recommended frequencies set by the Lebanese Food pyramid guideline [29]. The frequencies of daily intakes considered adequate for the Lebanese population are six servings and more for starch, 2 servings for fruits, 2-3 servings for vegetable, 2-3 serving for fat, 3 servings for milk and dairy products, 5-6 servings for meat, 3-4 cups for caffeinated drinks and never or rarely for sweets, fresh juices, commercial juices, sodas and energy drinks [29]. The degree of exposure to night shift work was determined by the number of years of experience as a night shift worker and the number of night shift hours over the entire work history. BMI and waist circumference were considered as the indicators of overweight and obesity. A BMI> 25 $\mathrm{kg} / \mathrm{m}^{2}$ and a waist circumference $>88 \mathrm{~cm}$ in women and $>102 \mathrm{~cm}$ in men were considered as abnormal results [30]. The level of physical activity was 
evaluated as follows: "inactive" for those who do not practice any physical activity outside their occupation, "moderately active" for those who practice at least two times per week and "very active" for those who practice for more than three times per week.

\subsection{Statistical analysis}

The data obtained were analyzed using the SPSS 22 statistical package. Chi-square test, Odds Ratio and logistic regressions were used to determine the relationships between night work, eating habits and the risk of obesity. T-test was used to compare the daily average consumption of the different food groups and beverage items with the daily average consumption of the same foods and beverages as recommended by the Lebanese food pyramid guideline. The threshold of significance was set at $p<0.05$.

\section{Results}

The demographic, occupational and behavioral characteristics of the participants are presented in Table 1.

Table 1: Demographic, occupational and behavioral characteristics of the participant

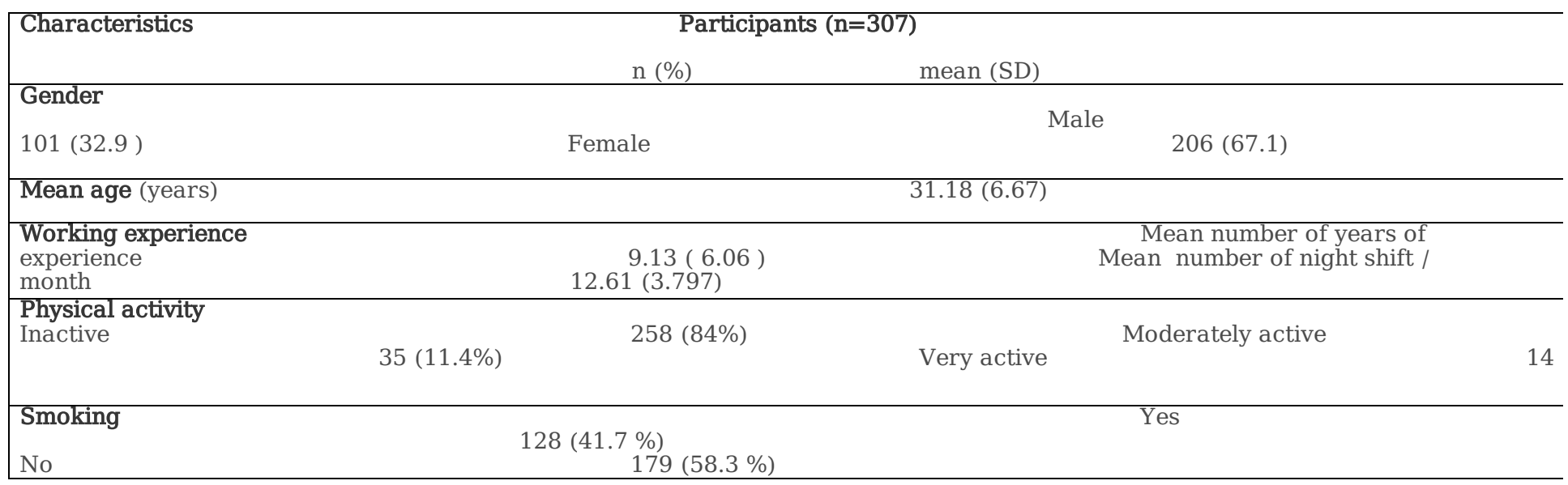

About $78.2 \%$ of nurses had an irregularity in meals timing which contributed to a significant decrease in the number of complete meals consumed during the day after a night shift work $(\mathrm{p}=0.000<0.05)$, and to an increase in the number of snacks consumed during night at work $(\mathrm{p}=0.015<0.05)$. Our findings highlighted that the most consumed snacks during night were sweets for $50 \%$ of nurses, potato chips for $34.4 \%$, fruits for $11.82 \%$ and baked goods for $3.76 \%$. While the daily intake of fruits $(t=25.244 / \mathrm{p}<0.05)$ and vegetables $(\mathrm{t}=$ 24.285 / $\mathrm{p}<0.05$ ) was significantly lower than the daily recommended amounts set by the Lebanese Food pyramid guideline, the intake of fats, sweets, commercial juices, sodas and energy drinks was significantly higher $(\mathrm{p}=0.000<0.05)($ Table 2$)$. Of those who reported drinking excess caffeinated drinks overnight, $60.9 \%$ did so in order to stay awake. In addition, our results showed that $45.3 \%$ of nurses brought with them homemade dishes for dinner while only $29.6 \%$ preferred to consume fast food.

Table 2: Daily mean frequencies of consumption of the different group of foods and beverages of the study population compared to the recommendation set by the Lebanese food guide pyramid .

\begin{tabular}{|c|c|c|c|c|}
\hline & & ipant (n & & \\
\hline & Daily Recommended value & mean & $\mathrm{t}$ & $\mathrm{p}$ \\
\hline Starch & 6 & 5.83 & 1.623 & 0.106 \\
\hline Fruits & 3 & 1.15 & 25.24 & 0.000 \\
\hline Vegetables & 3 & 1.25 & 24.285 & 0.000 \\
\hline Milk and milk products & 3 & 0.95 & 36.359 & 0.000 \\
\hline Meat and meat products & 5 & 3.62 & 19.195 & 0.000 \\
\hline Fats & 3 & 4.96 & 31.008 & 0.000 \\
\hline Desserts & 0 & 1.76 & 16.751 & 0.000 \\
\hline Caffeinated beverages & 4 & 2.36 & 13.294 & 0.000 \\
\hline Commercial juices & 0 & 0.52 & 9.244 & 0.000 \\
\hline Sodas and energy drinks & 0 & 1 & 10.932 & 0.000 \\
\hline
\end{tabular}


Table 3: Means (SD) of anthropometric measures and prevalence of overweight/obesity in the study population.

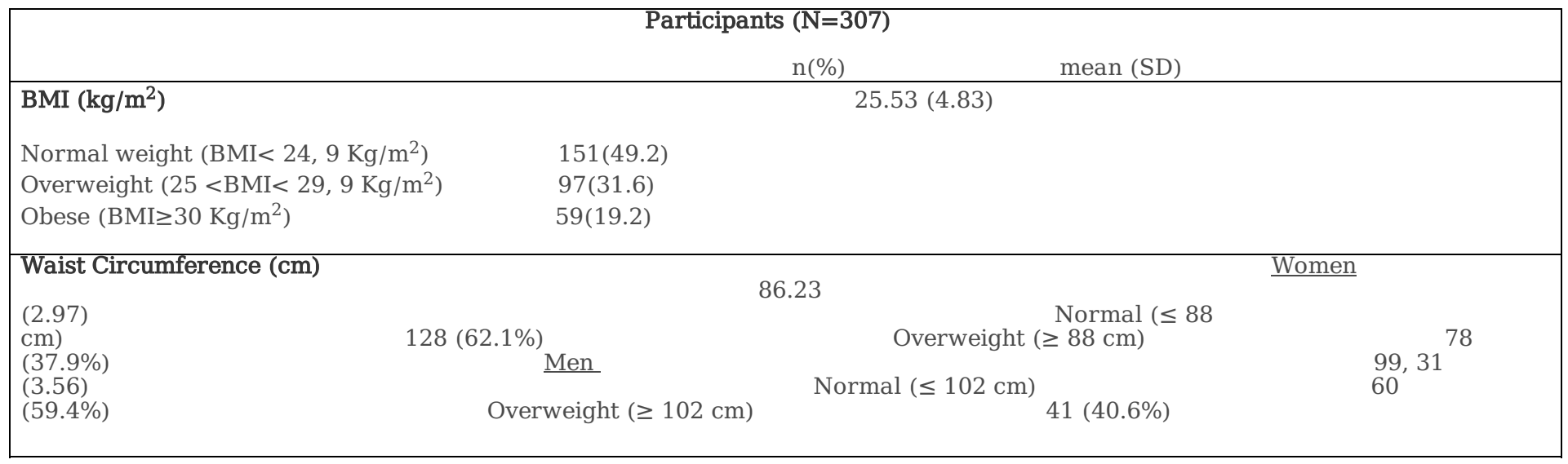

BMI and waist circumference in both women and men increased proportionally with the number of years of experience and the cumulative number of night shift hours over the entire work history $(p<0.05)$ (table 4$)$. However, no significant relationships were found between BMI / WC and the level of physical activity $(p=0.729 / p=0.218)$, the number of meals consumed during the day ( $p=0.476 / p$ $=0.572)$, the irregularity in meals timing $(\mathrm{p}=0.684 / \mathrm{p}=0.816)$, the number of snacks $(\mathrm{p}=0.615 / \mathrm{p}=0.256)$ and type of snacks $(\mathrm{P}=$ $0,794 / \mathrm{p}=0.924$ ) consumed during night.

Table 4: Association between night shift work characteristics and anthropometric measure in the study population

\begin{tabular}{|c|c|c|c|}
\hline \multirow[b]{2}{*}{ Night shift work characteristics } & \multicolumn{3}{|c|}{ coefficient of correlation ( $r$ ) ( $p$ value) } \\
\hline & BMI & WC (Women) & WC (Men) \\
\hline Number of year of experience & $0.175(0.002)$ & $0.346(0.000)$ & $0.178(0.045)$ \\
\hline $\begin{array}{l}\text { Cumulative number of night shift hours } \\
(0.012)\end{array}$ & $0.135(0.018)$ & $\begin{array}{l}0.284(0.000) \\
\text { over the entire work }\end{array}$ & 0.250 \\
\hline
\end{tabular}

\section{Discussion}

This cross-sectional study aimed to evaluate the relationship between night shift work, eating habits and BMI among nurses in Beirut. Our findings showed that night shift work affects eating habits and food choices and leads, as a result, to unhealthy eating patterns among Lebanese nurses. Similar to other authors [9, 23, 31, 32], we found that irregularity in meal timing, excessive snacking during night and consumption of high-fat and high sugar foods were common among night shift nurses. About $78.2 \%$ of nurses did not take their meals at regular times $(p<0.05)$. After their night shift, they did not take their breakfast because of a lack of appetite. They went directly to bed and had their first meal only after waking up. That irregularity in meals timing contributed to a reduction in the number of complete meals consumed during the day and to an increase in the number of snacks consumed during night. As other studies $[31,32,23,33,34]$, we found that the most consumed snacks during night were high fat and high sugar foods such as sweets and potato chips. Only a minority of nurses tended to snack on fruits. According to Reed [35], stress is the main reason for which night shift nurses usually crave for high fat and high sugar foods during their work.

What seems interesting in our study is that, the majority of nurses (45.3\%) brought home-made meals with them for dinner while only $29.6 \%$ regularly consumed fast food. These later did so not by preference for that type of food but by obligation because they did not always manage to take foods with them at work. On one hand, our findings contradict the results of a study carried out on 395 nurses in Saudi Arabia [36] which showed that night shift nurses consume more fast food at work because they like it. On other hand, this study supports the results of other researchers who had concluded that some night workers eat fast food at night not because they like it but because it is the most common type of food easily obtained overnight [34, 31].

In addition, our results identified that $60.6 \%$ of nurses consumed caffeinated drinks during night in order to stay awake ( $p<0.05)$. Reeves et al [22], in their study reported similar results. They confirmed that night shift nurses tended to consume more stimulants such as coffee and tobacco to be more active during night. However, when it comes to smoking our findings showed that night shift work is not the main reason for which some nurses smoke. In fact, on a total of $307,128(41.7 \%)$ nurses had started smoking long before they were hired. 
Our findings showed that night shift work leads to an unbalanced diet and reduce the level of physical activity among night shift nurses. The majority of nurses (84\%) did not practice any physical activity outside their occupation because they did not have enough time or because they felt too tired after their night shift $(\mathrm{p}<0.05)$. Indeed, some authors $[26,25]$ explained that night shift nurses do not engage in any physical activity even when they have time to exercise because of the fatigue associated with the nature of their work.

In our study, $56 \%$ of nurses had reported weight gain since the start of their work. After taking into consideration the age and gender of the study population, we found that BMI and waist circumference increased with the number of years of work and the cumulative night shift hours over the entire work history ( $p$ $<0.05$ ). Several studies showed similar results and confirmed that night shift work contributes to an increase in BMI and waist circumference and leads to weight gain $[18,13,15,16,19,14,20]$. Some authors $[21,22]$ had confirmed that the weight gain associated with night work was probably the consequence of an excess of calorie intake during night and a lack of physical activity. In this study, our findings have shown that night work leads to a perturbation of eating habits and to an increase in BMI which can lead to overweight and obesity. However, unlike previous researches [21, 20, 25, 22, 37 ], our results highlighted that the increase in BMI and the risk of overweight and obesity associated with night shift work was not related to the eating habits of nurses. The increase in BMI and waist circumference among our participants was not significantly associated with irregularity in meals timing, number of complete meals consumed during the day and number and type of snacks consumed during night $(p>0.05)$.

Nutritional interventions would certainly prevent and / or limit the physical symptoms associated with night shift work. Practical strategies allowing night shift nurses to adopt more structured and balanced diet can be put in place with the help of a nutritionist. In this case, it is first necessary to make employers understand that night shift work has harmful effects on the health of employees and then to work in collaboration with them to implement these strategies. We could then consider monitoring the nurses over a well-defined time in order to observe the effect of these interventions and strategies. Irregular meal times, snacking, lack of physical activity, and limited food supply at night are challenges that need to be improved to reduce the risk of overweight and obesity associated with night work.

\section{Study Limitations}

The sample size representative of the general population for this study was to be recruited from all hospitals localized in Beirut. Some hospitals refused to collaborate for administrative reasons and others were excluded from our study because they had a limited number of nurses. Thus only five hospitals were retained. However these five participating hospitals are among the largest hospitals in Beirut and include a significant number of nurses, so our sample size was not significantly affected. This study was a cross-sectional and not a correlational study. We were just observing that there is an association between night shift work, eating habits and BMI among Lebanese nurses. Therefore, we cannot end up with a cause and effect and conclude that night shift is the main cause of overweight and obesity among night shift nurses. Another point is that, as anthropometric measures we were able to take just the BMI and waist circumference. BMI do not distinguish between fat and lean mass and not a sufficient tool in measuring obesity.

\section{Conclusion}

This study showed that night shift nurses have poor eating habits which lead to an imbalance in their diet. They consume more foods with high energy values but fewer nutrient dense foods. In addition, they tend to consume more snacks than complete meals and do not practice any physical activity outside their work. However, weight gain and increased BMI and waist circumference observed among night shift nurses is not due to their eating habits. It seems appropriate to carry out more advanced research in order to better understand the process by which night work leads to weight gain and to an increase in the risk of obesity.

\section{List Of Abbreviations}

BMl: Body Mass Index

FFQ: Food Frequency Questionnaire

\section{Declarations}

\section{Ethic approval and consent to participate}

This research project was evaluated and approved by the ethics and research committee of the Holy Spirit University of Kaslik (USEK) and each of the five participating hospitals in order to conduct this study in the best conditions and to have access to the sample of the study.

\section{Consent to publish}

All the authors warrants that this article has not been published before, is not being concurrently submitted to and is not under consideration by another publisher. All the Author hereby consents to publication of the article in BMC Nursing.

\section{Availability of data and materials}

Data will not be shared. For having this data, please contact ZS at zeinabsamhat@hotmail.com

\section{Competing interests}

All authors declare that they have no competing interests. 


\section{Funding}

No funding was received in relation to this research project. ZS received a student support from the Holy Spirit University of Kaslik (USEK) to support study realization.

\section{Author contributions}

ZS, RA and YS contributed to the conception, design, data collection, statistical analysis, data interpretation, manuscript drafting, and approval of the final version of the manuscript and agreed for all aspects of the work.

\section{Acknowledgments}

The authors would like to thank the participating nurses for their contribution to the data collection. Also, the authors are grateful to the five hospitals for allowing their nurses to participate in the survey.

\section{Disclosure}

All authors have read and approved the final article.

\section{References}

[1] Organisation Internationale du Travail (OIT) : Liban- Code du travail. http://www.ilo.org/dyn/natlex/docs/WEBTEXT/39255/64942/F93LBN01.htm (1996). Accessed 12 Feb 2017

[2] Ntawuruhunga E, Chouanière D, Danuser B, Praz- Christinaz S M. Effets du travail de nuit sur la santé. Revue Médicale Suisse. 2008; 4:2581-2585.

[3] Von Treuer K, Fuller-Tyszkiewicz M, Little G. The impact of shift work and organizational work climate on health outcomes in nurses. Journal of occupational health psychology. 2014; 19(4): 453-461; Doi: 10.1037/a0037680.

[4] Akbari, H.,Mirzaei, R.,Nasrabadi, T., \&Gholami-Fesharaki,M. Evaluation of the Effect of Shift Work on Serum Cholesterol and Triglyceride Levels. Iranian Red Crescent medical journal. 2015; 17 (1), e18723. DOI: 10.5812/ircmj.18723

[5] Wang, F., Zhang, L., Zhang, Y., Zhang, B., He, Y., Xie, S., Li, M., Miao, X., Chan, E. Y. Y., Tang, J. L., Wong, M. C. S., Li, Z., Yu, I. T. S, \&Tse, L. A. Meta-analysis on night shift work and risk of metabolic syndrome: Obesity Comorbidity/Etiology. Obesity Reviews. 2014; 15 (9), 709-720.doi: 10.1111/obr.12194.

[6] Knutsson, A. Health disorders of shift workers. Occupational medicine. 2003; 53 (2), 103-108.

[7] Hansen, A.,Stayner, L.,Hansen, J., \& Andersen, Z.Night shift work and incidence of diabetes in the Danish Nurse Cohort. Occupational and environmental medicine. 2016; 73(4), 262 - 268. DOI: 10.1136/oemed-2015-103342.

[8] Pietroiusti, A.,Neri, A.,Somma, G., Coppeta, L.,lavicoli, I., Bergamaschi, A., \&Magrini, A . Incidence of metabolic syndrome among night-shift healthcare workers. Occupational and environmental medicine. 2010; 67 (1), 54-57.DOI: 10.1136/oem.2009.046797.

[9] Rohmer O, Bonnefond A, Muzet A, Tassi P. Etude du rythme veille/sommeil, de l'activité motrice générale et du comportement alimentaire de travailleurs postés obèses: l'exemple des infirmières. Le travail humain. 2004; 67 (4) :359 - 376.

[10]Valléry, G., Hervet, C. Impact de diverses modalités organisationnelles du travail posté sur le sommeil, les comportements alimentaires , la vie sociale et familiale : le cas du personnel soignant en milieu hospitalier français. PISTES-Perspectives Interdisciplinaires Sur le Travail Et la Santé. 2005 ; 7 (1), 1-30.

[11] Macagnan J, Pattussi M P, Canuto R, Henn R L, Fassa A G, Olinto M T. Impact of nightshift work on overweight and abdominal obesity among workers of a poultry processing plant in southern Brazil. Chronobiology international. 2012; 29 (3): 336-343; Doi : 10.3109/07420528.2011.653851

[12] Proper K, Van De Langenberg D, Rodenburg W, Vermeulen R, Van Der Beek A, VanSteeg H, Van Kerkhof L. The relationship between shift work and metabolic risk factors: A systematic review of longitudinal studies. American Journal of Preventive Medicine. 2016; 50 (5): 147-157; Doi:

10.1016/j.amepre.2015.11.013.

[13] Di Lorenzo L, De Pergola G, Zocchetti C, L'Abbate N, Basso A, Pannacciulli N, Cignarelli M, Giorgino R, Soleo L. Effect of shift work on body mass index: results of a study performed in 319 glucose-tolerant men working in a Southern Italian industry. International Journal of Obesity. 2003; 27 (11):1353-1358; doi: 10.1038/sj.ijo.0802419.

[14] Zhao I, Turner C. The impact of shift work on people's daily health habits and adverse health outcomes. Australia Journal of Advanced Nursing. 2008; 25(3): 8-22.

[15] Griep R H, Bastos L S, Fonseca M J M, Silva-Costa A, Portela L F, Toivanen S, Rotenberg L. Years worked at night and body mass index among registered nurses from eighteen public hospitals in Rio de Janeiro, Brazil. BMC health services research. 2014; 14(1): 63; Doi: 10.1186/s12913-014-0603-4.

[16] Kim M, Son K, Park H, Choi D, Yoon C, Lee H, Cho E, Cho M. Association between shift work and obesity among female nurses: Korean Nurses' Survey. BMC public Health. 2013; 13 (1): 1204; Doi: 10.1186/1471-. 
[17] Lee G, Kim K, Kim S, Kim J, Suh C, Son B, Lee C. Choi, J. Effects of shift work on abdominal obesity among 20-39-year-old female nurses: a 5-year retrospective longitudinal study. Annals of Occupational and Environmental Medicine. 2016; 28 (1): 69; Doi : 10.1186/s40557-016-0148-6.

[18] Buchvold H V, Pallesen S, Øyane N M F, Bjorvatn B. Associations between night work and BMl, alcohol, smoking, caffeine and exercise-a cross-sectional study. BMC public health. 2015; 15: 1112; doi: 10.1186/s12889-015-2470-2.

[19] Smith P, Fritschi L, Reid A, Mustard C. The relationship between shift work and body mass index among Canadian nurses. Applied Nursing Research. 2013; 26 (1): 24-31; Doi : 10.1016/j.apnr.2012.10.001.

[20] Peplonska B, Bukowska A, Sobala W. Association of Rotating Night Shift Work with BMI and Abdominal Obesity among Nurses and Midwives. PLoS ONE. 2015; 10 (7): 1-14; DOI: 10.1371/journal.pone.0133761.

[21] Geliebter A, Gluck M, Tanowitz M, Aronoff N, Zammit G. Work-shift period and weight Change: Applied nutritional investigation. Nutrition . 2000 ; 16 (1) : 27-29 ; doi: 10.1016/S0899-9007(99)00228-2

[22] Reeves S, Newling-Ward E, Gissane C. The effect of shift-work on food intake and eating habits. Nutrition \& Food Science. $2004 ; 34$ (5): 216 - 221; Doi : $10.1108 / 00346650410560398$.

[23] Délèze C, Trummer T. Les influences du travail de nuit sur la qualité de vie des infirmières. Thèse pour l'obtention du diplôme Bachelor of Sciences HES-SO en soins infirmiers, HES-SO Valais.2010.

[24] Freitas E, Canuto R, Henn R L, Olinto B A, Macagnan J B A, Pattussi M P, Busnello F M, Olinto M T A. Alteration in eating habits among shift workers of a poultry processing plant in southern Brazil. Ciência\&SaúdeColetiva. 2015; 20(8): 2401; DOI: 10.1590/1413-81232015208.18642014.

[25] Persson M, Martensson J. Situations influencing habits in diet and exercise among nurses working night shift. Journal of Nursing Management. 2006; 14 (5) : 414-423; Doi: 10.1111/j.1365-2934.2006.00601.x.

[26] Ulhôa M A, Marqueze E C, Burgos L G A, Moreno C R C . Shift Work and Endocrine Disorders. International Journal of Endocrinology. 2015: 1-11; DOI: $10.1155 / 2015 / 826249$.

[27] Barton J, Spelten E, Totterdell P, Smith L, Folkard S, Costa G. The Standard Shiftwork Index: a battery of questionnaires for assessing shiftwork-related problems. Work and stress. 1995; 9 (1): 4-30.

[28]University of Cambridge. EPIC-Norfolk Food Frequency Questionnaire and FETA Software. http://www.srl.cam.ac.uk/epic/epicffq/. (2003). Accessed 6 April 2017.

[29] American University of Beirut (AUB). The Lebanese cedar food guide. https://www.aub.edu.lb/fafs/nfsc/Documents/LR-e-FBDG-EN-III.pdf. (2013). Accessed 7 April 2017.

[30] World Health Organization (WHO). Obesity and overweight. http://www.who.int/mediacentre/factsheets/fs311/en/. (2016). Accessed 14 Feb 2017

[31] Cain S, Filtness A, Phillips C, Anderson C. Enhanced preference for high-fat foods following a simulated night shift. Scandinavian journal of work, environment \& health. 2015; 41 (3): 288 - 293; doi: 10.5271/sjweh.3486

[32] De Assis M AA, Nahas M V, Bellisle F, Kupek E. Meals, snacks and food choices in Brazilian shift workers with high energy expenditure. Journal of Human Nutrition and Dietetics. 2003 ;16 (4) : 283-289;doi: 10.1046/j.1365-277X.2003.00448.x

[33] Hemiö, K.,Puttonen, S.,Viitasalo, K.,Härmä, M.,Peltonen, M., \&Lindström, J. Food and nutrient intake among workers with different shift systems. Occupational and Environmental Medicine. 2015; 72 (7), 513 - 520.DOI: 10.1136/oemed-2014-102624

[34]Wong, H., Wong, M., Wong, S., Lee, A. The association between shift duty and abnormal eating behavior among nurses working in a major hospital: A cross-sectional study. International Journal of Nursing Studies. 2010 ; 47 (8), 1021-1027. Doi: 10.1016/j.ijnurstu.2010.01.001.

[35] Reed, D. Healthy Eating for Healthy Nurses: Nutrition Basics to Promote Health for Nurses and Patients. Online Journal Of Issues In Nursing. 2014; 19 (3), 7. Doi : 10.3912/OJIN.Vol19No03Man07.

[36] Almajwal A. Stress, shift duty, and eating behavior among nurses in Central Saudi Arabia. Saudi Medical Journal. 2016;37(2): 191-198; Doi : 10.15537/smj.2016.2.13060.

[37] Taheri S, Lin L, Austin D, Young T, Mignot E. Short sleep duration is associated with reduced leptin, elevated ghrelin, and increased body mass index. PLoS Med.2004; 1 (3): 62.

\section{Supplementary Files}

This is a list of supplementary files associated with this preprint. Click to download.

- Dataspss..sav 